laboratoires CNR grippe et 6 laboratoires hospitaliers de virologie. De manière harmonisée dans l'ensemble de ces laboratoires était réalisé un criblage de diagnostics différentiels : toutes les PCR étaient mises à disposition et le délai de réponse était inférieur à $48 \mathrm{~h}$. Concernant le diagnostic du coronavirus, avant le 28 avril, une culture était réalisée (manipulation en laboratoire $\mathrm{P}_{3}$ ), uniquement à l'institut Pasteur. Après le 28 avril, une PCR spécifique, validée par I'Institut Pasteur, a êté mise au point et utilisée dans les laboratoires sélectionnés.

La structure du coronavirus responsable de SRAS est similaire à celle des autres coronavirus (responsables de pathologies respiratoires bénignes de type rhumes, parfois sévères chez le jeune enfant ou le vieillard). Toutefois, les données de biologie moléculaire issues du séquençage, obtenues dès mi-avril, ont montré qu'il s'agissait d'un virus totalement différent.

Un an après cette épidémie, quelques inconnues subsistent, notamment l'origine de ce virus, son réservoir animal (la civette ?) ou la possibilité de résurgences.

\section{V - ET LA GRIPPE AVIAIRE?}

L'épidémie de SRAS nous a permis d'être entrainés à la gestion d'autres crises dont une est récemment apparue : la grippe aviaire. Au moment des premiers cas de SRAS (le 19 février) étaient détectés 2 cas de grippe aviaire $\mathrm{H}_{5} \mathrm{~N}_{1}$ à Hong Kong ayant entrainé un décès. Déjà en 1997, une épidémie à $\mathrm{H}_{5} \mathrm{NI}$ avait atteint 18 personnes en tuant 6 (mortalité $33 \%$, virus hautement pathogène). L'épidémie avait alors été maîtrisée par l'abattage de tous les élevages de poulet.

Actuellement, cette nouvelle épizootie touche 9 pays d'Asie et la politique mise en place est similaire à celle développée pour le SRAS. L'OMS coordonne de nouveau un réseau de laboratoires qui travaillent de manière intensive sur ce virus. Un traitement par antineuraminidase est disponible et efficace.

En février 2004, 15 cas étaient confirmés, exclusivement au Vietnam et en Thaillande ; 30 millions de poulets ont été abattus, mais le contrôle de l'épidémie reste difficile du fait de 'micro-élevages' répandus dans ces pays et d'un abattage sans compensation financière...

Ainsi, bien que l'on ne maîtrise pas totalement cette épizootie, les structures qui à terme permettront ce contrôle, sont mises en place. Un vaccin $\mathrm{H}_{5} \mathrm{~N}$ I devrait être disponible dans quelques mois.

Sachant qu'aucune transmission interhumaine n'a été montrée, la prévention passe par l'évitement des réservoirs animaux (endroits où l'on trouve les déjections de poulets).

Aucune restriction de voyage dans ces pays n'a été prononcée à ce jour.

\title{
Le pré-analytique en biologie médicale
}

\section{Importance du pré-analytique en biologie médicale}

\section{Pr A. LEGRAND}

Laboratoire de Biochimie, CHUl de Bicètre

Dans la réalisation d'une analyse, le pré-analytique occupe plus de la moitié du temps. Il s'agit d'une phase essentielle dont une partie est interne au laboratoire et une autre se situe en amont, du patient jusqu'à l'arrivée de l'échantillon. Les acteurs du pré-analytique sont nombreux, incluant le préleveur, le transporteur et l'équipe du laboratoire.

\section{Suivi et contrôle de la phase pré-analytique (diapositive 5)}

Concernant le patient et son état, le GBEA prévoit l'utilisation de fiches de suivi médical pour le laboratoire exécutant, comportant au minimum l'identité du patient, la prescription et le délai d'attente ainsi que les renseignements cliniques nécessaires. Cette fiche est recommandée, mais non obligatoire.

Concernant les conditions liées aux analyses c'est-à-dire les règles de bonne exécution, conservation, transport des échantillons, il n'y a pas de règles opposables. C'est pourquoi la précédente Commission du Contrôle de Qualité, sous l'égide de M. Samama et de M. BaufineDucrocq, a mis en place un groupe de travail pour établir des fiches

\section{Diapositive 5 : Place et acteurs du pré-analytique}

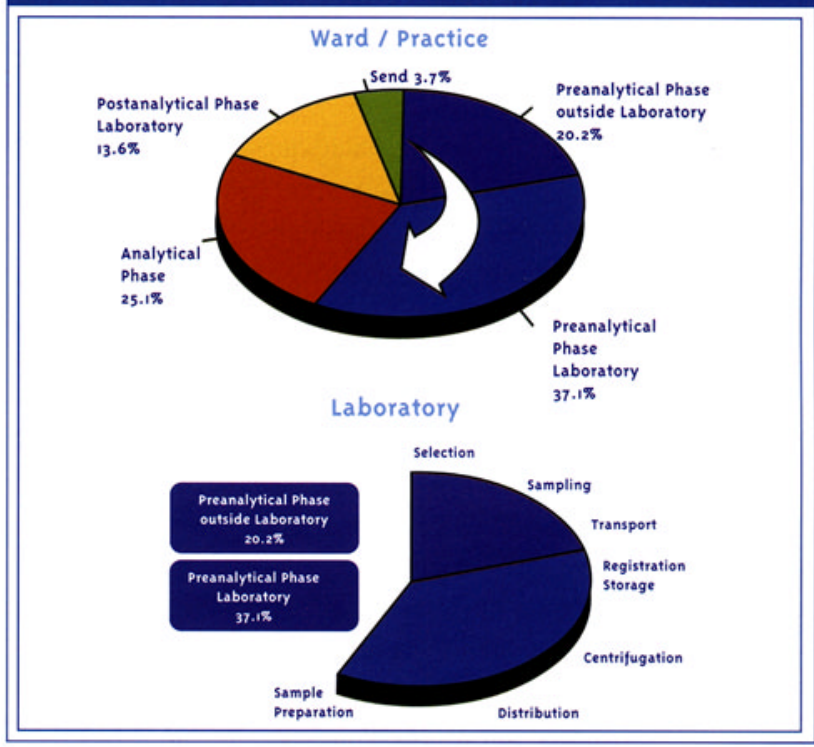

destinées aux personnels extérieurs au laboratoire, impliqués dans la phase pré-analytique. Ces fiches dont 163 sont d'ores et déjà établies en biochimie, hématologie, microbiologie et parasitologie, seront prochainement diffusées et cette démarche sera poursuivie dans le cadre de la Commission actuelle. 